\title{
Formulation of detection bioconjugates of gold coated iron oxide nanoparticles for aflatoxin M1 in milk
}

\author{
Jayesh H Kabariya ${ }^{1}$ and Vimal M Ramani ${ }^{2 *}$ \\ ${ }^{1}$ Senior Research Fellow, Postgraduate Institute of Dairy Education and Research, Kamdhenu University, \\ Amreli, Gujarat \\ ${ }^{2}$ Principal and Dean, College of Dairy Science and Postgraduate Institute of Dairy Education and Research, \\ Kamdhenu University, Amreli, Gujarat, India
}

\begin{abstract}
Mycotoxins particularly aflatoxins are gaining increasing importance due to their deleterious effects on human and animal health and also due to ubiquitous presence of aflatoxigenic fungi in all the agricultural products. Corn, groundnuts and other plants were infected by Aspergillus flavus \& Aspergillus parasiticus and secrete the mycotoxins. Aflatoxin B1 transmitted to cow by feeding these infected plants and aflatoxin B1 transformed into its hydroxylated product such as aflatoxin M1 and M2 and such aflatoxin secreted in cow milk. In the present study, we explored the nanobiotechnology approach to prepare detection bioconjugates of gold coated iron oxide nanoparticle for the detection of aflatoxin M1 in milk. Gold coated iron oxide nanoparticles (Au-Fe304 NPs) ranging between 10-20 $\mathrm{nm}$ were synthesized by co-precipitation method and functionalized by EDC-NHS then labeled with FITC-labeled streptavidin (FITC-STV). Biotinylated aflatoxin M1 (biAFM1) specific to monoclonal anti-aflatoxin M1 antibodies (mAFM1) were prepared, separately. The fluorophore FITC-STV-Au- $\mathrm{Fe}_{3} \mathrm{O}_{4} \mathrm{NPs}$ and bimAFM1 antibodies were allowed to interact to obtain $\mathrm{Au}-\mathrm{Fe}_{3} \mathrm{O}_{4}$ NPs-FITC-STV-bimAFM1 antibody and AFM1 bioconjugates. The bioconjugates were characterized by Transmission Electron Microscope (TEM), Scanning Electron Microscope with Energy Dispersive X-ray (SEM-EDAX), Fourier Transform Infrared (FTIR), Particle Size Analyzer with zeta potential (PSA) and Fluorescence Microscopy. The bioconjugation formation was confirmed by pinkish red color in bright flied microscopy same field observed by fluorescence microscopy shows the green fluorescence which confirm the aggregation between $\mathrm{Au}-\mathrm{Fe} 304$ NPs-FITC labeled STV-bimAFM1 antibody and AFM1.
\end{abstract}

KEY WORDS: AFLATOXIN M1, BIOCONJUGATES, GOLD COATED IRON NANOPARTICLE, MONOCLONAL ANTIBODY AFM1

\section{ARTICLE INFORMATION:}

*Corresponding Author: vimamramani@gmail.com Received $1^{\text {st }}$ July, 2018

Accepted after revision $19^{\text {th }}$ Sep, 2018

BBRC Print ISSN: 0974-6455

Online ISSN: 2321-4007 CODEN: USA BBRCBA

\%:\% Thomson Reuters ISI ESC / Clarivate Analytics USA and

: Crossref Indexed Journal

NAAS Journal Score 2018: 4.31 SJIF 2017: 4.196

- A Society of Science and Nature Publication, Bhopal India 2018. All rights reserved.

Online Contents Available at: http//www.bbrc.in/

DOI: $10.21786 / \mathrm{bbrc} / 11.3 / 13$ 


\section{INTRODUCTION}

From the last decade iron oxide nanoparticles $\left(\mathrm{Fe}_{3} \mathrm{O}_{4}\right.$ NPs) and their combinations with gold (core/shell) has become more attractive because of their vast applications in different fields such as biosensor, medical field and drug delivery etc. The surface binding of various chemical and biological molecules onto gold particle was due to thiol chemistry of gold surface for attachment of functionalized compounds (Kouassi et al., 2007). Gold coated iron oxide nanoparticle ( $\mathrm{Au}-\mathrm{Fe}_{3} \mathrm{O}_{4} \mathrm{NPs}$ ) were synthesized by reduction of metal with sodium borohydride through sonication method (Baniukevic et al., 2013). Using hydroxylamine as a reducing agent gold (shell) coated iron oxide (core) nanoparticle also synthesized by iterative reduction method and it analyze by transmission electron microscope (TEM) and superconducting quantum interference device (SQUID) magnetometer reported (Lyon et al., 2004). The measurement of fluorescent and optical properties of $\mathrm{Au}-\mathrm{Fe}_{3} \mathrm{O}_{4} \mathrm{NPs}$ has been reported by (Baniukevic et al., 2013 Carrasco et al., 2018).

Corn, groundnuts and other plants were infected by Aspergillus flavus and Aspergillus parasiticus and secrete the mycotoxins which is responsible for the food born disease. Corn, groundnuts and other plants were infected by Aspergillus flavus and Aspergillus parasiticus and secrete the mycotoxins. Aflatoxin B1 transmitted to cow by feeding these infected plants and aflatoxin B1 transformed into its hydroxylated product such as aflatoxin M1 and M2 and such aflatoxin secreted in cow milk which quite stable during storage, pasteurization and milk product preparation (Stroka \&t Anklam, (2002). The aflatoxin is high temperature resistant and is not inactivated after milk treatment processes such as pasteurization, sterilization and others. Mycotoxins particularly aflatoxins are gaining increasing importance due to their deleterious effects on human and animal health and also because of ubiquitous presence of aflatoxigenic fungi in all the agricultural products. Animals contact to mycotoxins by consumption of infected food, it may be harmful to their health as well as humans, who are consumers of the animal products such as milk (Gacem and Hadj-Khelil 2016, Ketney et al., 2017).

Aflatoxin is a kind of mycotoxin that was discovered from the mass poisoning of turkeys in Britain in 1960, and has strong carcinogenicity. Aflatoxin M1 (AFM1) is hydroxylated product of aflatoxin B1. Numerous diagnostic methodology like, chromatographic method includes, TLC, HPLC and OPLC, FT-NIR and enzymelinked immunosorbent assay (ELISA) were available for the detection of aflatoxins but it is time consuming and requiring sophisticated instruments as well as trained manpower (Espinosa et al., 2011). Diagnostic immu- noassay have been use with specific antigen antibody interaction for the detection of many molecules such as AFM1 because of their sensitivity, easy to handle and quantitatively measurements. In fluorescence microscopic technique antibody labeled with so many fluorescent dyes such as Fluorescein isothiocyanate (FITC), Rhodomine, Alexa fluor and other are used as an indicator which provide optical contrast for better analysis (Adarsha et al., 2015).

Till now, the use of gold coated iron oxide nanoparticle was comparatively less because it require more time to synthesis, require high temperature for the synthesis of nanoparticle and very difficult to prevent aggregation without chemical modification or use of surfactant. Here in this study, we have used simple and rapid method for the synthesis of gold coated iron oxide nanoparticle at room temperature by chemical co-precipitation, reduction of sodium borohydride and sonication method. In first step, synthesis of iron oxide nanoparticle as a core by chemical co-precipitation and then it coated with gold as shell by reduction of sodium borohydride with sonication to enhanced particle monodispersity. Then prepared particles were characterized by Transmission Electron Microscope (TEM), Scanning Electron Microscope with Energy dispersive X-ray (SEM-EDAX), Fourier Transform Infrared (FTIR), Particle Size Analyzer with zeta potential (PSA) and Fluorescence Microscopy. Surface charges and further modifications with mercaptopropionic acid and EDC-NHS also characterization by the same.

Our research effort is in direction of the detection of AFM1 with biotin-streptavidin binding approach by labeling of fluorescence dye with gold coated iron oxide nanoparticle. The bioconjugation formation between streptavidin-AFM1 and biotinylated monoclonal antibody of AFM1 was confirmed by fluorescence microscopy shows the fluorescence compounds which confirm the interaction. Mycotoxins particularly aflatoxins are gaining increasing importance due to their deleterious effects on human and animal health and also due to ubiquitous presence of aflatoxigenic fungi in all the agricultural commodities under field and storage conditions. Common established methodologies for aflatoxin detection include thin-layer chromatography (TLC), (Flores and Gonzalez 2017) and high performance liquid chromatography (HPLC) (Carrasco et al., 2018).

These techniques have excellent sensitivities but they require skilled operators, extensive sample pre-treatment and expensive equipments. The present investigation was an attempt to develop basic mechanism of new nanotechnology based detection system with a minimal size, weight and real low cost and rapid detection will have significantly impact the practice of monitoring program for aflatoxin. 


\section{MATERIAL AND METHODS}

All chemicals were obtained from commercial source and used as received. $\mathrm{FeSO}_{4} .7 \mathrm{H}_{2} \mathrm{O}, \mathrm{FeCl}_{3}, \mathrm{HAuCl}_{4}$, FITCstreptavidin, biotin and NHS-biotin, aflatoxin M1 (AFM1) were purchased from Sigma Aldrich (USA). Sodium hydroxide, perchloric acid, sodium borohydrate, cetyltrimetyl-ammonium bromide (CTAB), ethylene diamine tetra-acetic acid (EDTA), 3-mercaptopropionic acid, N-hydroxysuccinimide (NHS), N-Ethyl-N-(3-dimethyl-aminopropyl)-carbodimide, (EDC), streptavidin (STV), Dimethyl Sulfoxide (DMSO), phosphate buffer solution (PBS) at $\mathrm{pH}$ 7.4 HPLC grade pure water, were purchased from HiMedia (India). Aflatoxin M1 monoclonal antibody (mAFM1-Ab) were purchased from MyBiosource (USA). All chemicals materials were used as received.

The synthesis of $\mathrm{Fe}_{3} \mathrm{O}_{4}$ NPs were carried out by modified Massart's co-precipitation method. The ratio of iron salt (Fe(III)/Fe(II) was kept as 2:1 in an alkaline solution. Briefly, $0.64 \mathrm{M} \mathrm{FeCl}_{3}$ and $0.32 \mathrm{M} \mathrm{FeSO}_{4} \cdot 7 \mathrm{H}_{2} \mathrm{O}$ were dissolved in $40 \mathrm{ml}$ of deionized water and the solution was stirred (TARSON SPINOT DIGITAL) until the iron salt completely dissolved. Subsequently add $40 \mathrm{ml}$ of $1 \mathrm{M} \mathrm{NaOH}$ solution drop wise into stirred mixture and stirred it for 20minutes. The formation of $\mathrm{Fe}_{3} \mathrm{O}_{4}$ (magnetite) nanoparticle by indicating the color change from yellowish brown to black. The chemical reaction of magnetite precipitation may be written as follows (Tamer et al., 2010).

$$
\begin{array}{lll}
\mathrm{Fe}^{+2}+2 \mathrm{Fe}^{+3}+8 \mathrm{OH} & \rightarrow & \mathrm{Fe}_{3} \mathrm{O}_{4}+4 \mathrm{H}_{2} \mathrm{O} \\
\text { Yellowish color } & \text { Black color }
\end{array}
$$

The black color precipitate was separated by permanent magnet and washed with deionized water. To obtain oxidized magnetite nanoparticles, separated black precipitate was first washed with $2 \mathrm{M}$ perchloric acid and waited for 2-3 hours to oxidized iron salt to magnetite until the color was change from black to brown under inert condition. Then particle was centrifuged (REMI CM-12plus) at 10,000 rpm for 20 minutes. After centrifugation, discard the supernatant and washed with deionized water. Repeat he washing procedure for 2-3 times or until $\mathrm{pH}$ was reduced to neutral $\mathrm{pH}$. The gold coating procedure was carried out in the presence of CTAB to encapsulate the synthesized $\mathrm{Fe}_{3} \mathrm{O}_{4}$ NPs by gold as a shell. Briefly, $10 \mathrm{mg} \mathrm{Fe} \mathrm{O}_{4}$ NPs were add into 5ml 0.27M EDTA solution which prepared in $1 \mathrm{M} \mathrm{NaOH}$. The mixture was stirred in sonicator (LABMAN) at 30 amplitude for 5 minutes. Then resulting solution was centrifuge at $10,000 \mathrm{rpm}$ for 10 minutes. Supernatant was discarded and pellet was washed with deionized water. Washing procedure was repeated for 3 times. Then add $7 \mathrm{ml}$ of $0.1 \mathrm{M} \mathrm{CTAB}$, $3 \mathrm{ml} 0.01 \mathrm{M} \mathrm{HAuCl}_{4}$ and $300 \mu \mathrm{l} 1 \mathrm{M} \mathrm{NaOH}$ into resulting precipitation and stirred vigorously, subsequently add $150 \mathrm{mg}$ sodium borohydrate into stirred mixture and stirred vigorously for 3 minutes. The color was change from yellow to dark red indicated the gold was coated into core (iron oxide nanoparticles $\left(\mathrm{Fe}_{3} \mathrm{O}_{4} \mathrm{NPs}\right)$ as a shell (Tamer et al., 2010).

\section{SYNTHESIS OF GOLD COATED IRON OXIDE NANOPARTICLES WITH FITC LABELED STREPTAVIDIN AS A CARRIER MOLECULE}

$10 \mathrm{mg}$ gold coated iron oxide nanoparticles were added in $1 \mathrm{ml}$ of $20 \mathrm{mM}$ 3-mercaptopropionic acid and sonicated for 4 hours. After sonication particles were washed with pure water. This procedure createdf the carboxyl group onto surface of gold coated iron oxide nanoparticles with EDC and NHS linked and it was used as a carrier material for streptavidin binding. For cross link of carboxylated nanoparticles to EDC-NHS, first $5 \mathrm{mg}$ of nanoparticle was added into $2 \mathrm{ml}$ EDC $(0.05 \mathrm{mg} / \mathrm{ml}) \mathrm{solu}-$ tion containing $0.2 \%$ NHS prepare in cold water then it sonicate for 5 minutes at $4^{\circ} \mathrm{C}$, after sonication particles were separated out by using permanent magnet. After this process, add $1 \mathrm{ml}$ of $2 \mathrm{mM}$ streptavidin prepared in PBS (pH-7.4) in separated nanoparticle, mix it properly then incubate it for 2 hours.

Streptavidin fluorescently labelled with Fluorescein isothiocyanate (FITC) at a stock concentration of $1 \mathrm{mg} /$ $\mathrm{mL}$. This dye has an absorption peak at $495 \mathrm{~nm}$ and an emission peak of $525 \mathrm{~nm}$. The resultant FITC labeled streptavidin binded gold coated iron oxide nanoparticles were separated by permanent magnet from reaction mixture, then air dried for $12 \mathrm{~h}$ and resuspended in water. The procedure was repeated for three times to remove impurities (Eivari and Rahdar (2013). Anti-AFM1 monoclonal antibody having sulfosuccinimidyl group was prepared separately by covalently binding primary amines of antibody (Gretch (1987). 10mg (10mM) NHSbiotin solution in $1 \mathrm{ml}$ DMSO was added and dissolved in it and was prepared prior to use. Then was added monoclonal AFM1 antibody with $80 \mu \mathrm{g}$ of NHS-biotin/mg ratio, mixed immediately and was incubated for 3 hours in shaking condition. After incubation period dialysis procedure of NHS-biotin binded antibody was carried out at $4^{\circ} \mathrm{C}$ for overnight to remove unbinded NHS-biotin molecules. Subsequently, store the biotin labeled AFM1 antibody at $2-8^{\circ} \mathrm{C}$.

The procedure was started with $50 \mu$ l biotinylated monoclonal AFM1 antibody and 20 $\mathrm{Ll}$ streptavidin conjugated gold coated iron oxide nanoparticles were mix together and incubated at $4{ }^{\circ} \mathrm{C}$ for $1 \mathrm{~h}$ in dark condition. The biotinylated antibody had bound non-covalently to streptavidin and had formed bridge for direct sensing of aflatoxin M1. After the formation of nanoparticle bio- 
conjugate add $10 \mu \mathrm{l}$ AFM1, it was incubated at $4{ }^{\circ} \mathrm{C}$ for 30 minutes in dark condition. Characterization of bioconjgates aggregation was done by different techniques (Adarsha et al., 2015).

\section{RESULTS AND DISCUSSION}

\section{TRANSMISSION ELECTRON MICROSCOPE}

The morphological characterization iron oxide nanoparticle was done by transmission electron microscopy (TEM). A small drop of formulated iron oxide nanoparticle was placed on the copper grid surface and dried it at room temperature. TEM analysis was carried out by JEOL-JEM2100 transmission electron microscope.

The shape of nanoparticles was spherical having average dimension of $10.8 \pm 4.6 \mathrm{~nm}$. The TEM image of $\mathrm{Fe}_{3} \mathrm{O}_{4}$ NPs shows in Figure 1. The morphology and magnetic properties can be controlled by varying in $\mathrm{pH}$ solution, ionic strength, temperature, reaction time, type of salts and stirring speed. Eivari and Rahdar (2010) has reported that $\mathrm{Fe}_{3} \mathrm{O}_{4}$ NPs was almost spherical and their mean size was $10 \mathrm{~nm}$. Our TEM result of $\mathrm{Fe}_{3} \mathrm{O}_{4}$ NPs morphology is at par to this.
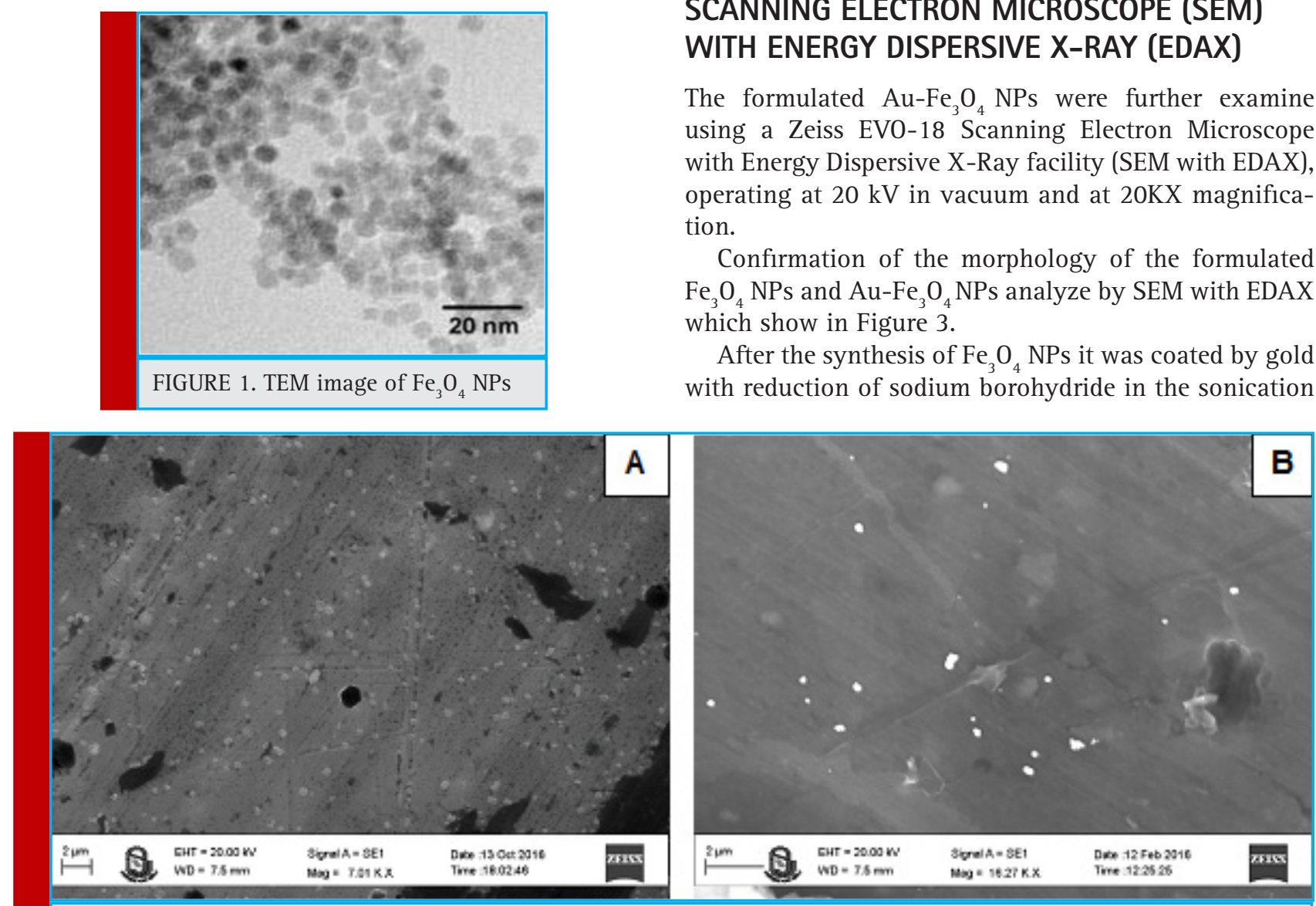

FIGURE 3. SEM images: (A) $\mathrm{Fe}_{3} \mathrm{O}_{4} \mathrm{NPs}(\mathrm{B}) \mathrm{Au}-\mathrm{Fe}_{3} \mathrm{O}_{4} \mathrm{NPs}$

Figure 2 shows that the $\mathrm{Au}-\mathrm{Fe}_{3} \mathrm{O}_{4}$ NPs was darker than $\mathrm{Fe}_{3} \mathrm{O}_{4}$ NPs. TEM images shows that the average particles size was increased from $10 \mathrm{~nm}$ to $14 \mathrm{~nm}$ after gold coating. The reduction of gold onto spherical surface of $\mathrm{Fe}_{3} \mathrm{O}_{4}$ NPs and it has average size of $\mathrm{Au}-\mathrm{Fe}_{3} \mathrm{O}_{4} \mathrm{NPs}$ was $14 \mathrm{~nm} \pm$ $3 \mathrm{~nm}$. Eivari and Rahdar (2010) has reported that the after coating of gold onto the $\mathrm{Fe}_{3} \mathrm{O}_{4}$ NPs it appear more darker than $\mathrm{Fe}_{3} \mathrm{O}_{4}$ NPs because of gold having more electron density then iron. Our TEM result of $\mathrm{Au}-\mathrm{Fe}_{3} \mathrm{O}_{4} \mathrm{NPs}$ is at par with them.

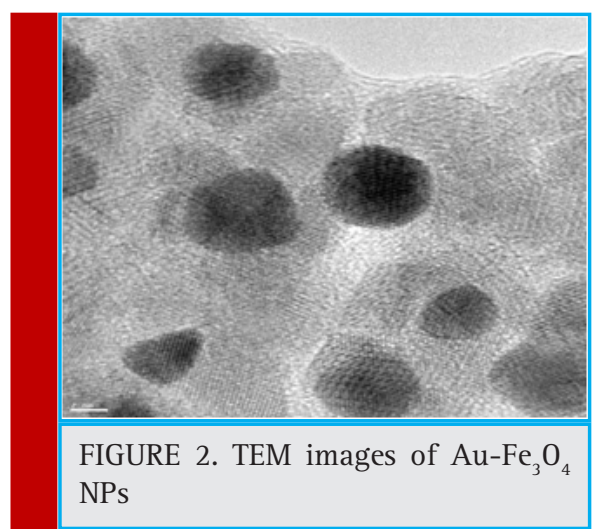

\section{SCANNING ELECTRON MICROSCOPE (SEM) WITH ENERGY DISPERSIVE X-RAY (EDAX)}

The formulated $\mathrm{Au}-\mathrm{Fe}_{3} \mathrm{O}_{4} \mathrm{NPs}$ were further examine using a Zeiss EVO-18 Scanning Electron Microscope with Energy Dispersive X-Ray facility (SEM with EDAX), operating at $20 \mathrm{kV}$ in vacuum and at 20KX magnification.

Confirmation of the morphology of the formulated $\mathrm{Fe}_{3} \mathrm{O}_{4} \mathrm{NPs}$ and $\mathrm{Au}-\mathrm{Fe}_{3} \mathrm{O}_{4}$ NPs analyze by SEM with EDAX which show in Figure 3.

After the synthesis of $\mathrm{Fe}_{3} \mathrm{O}_{4}$ NPs it was coated by gold with reduction of sodium borohydride in the sonication

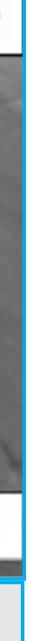




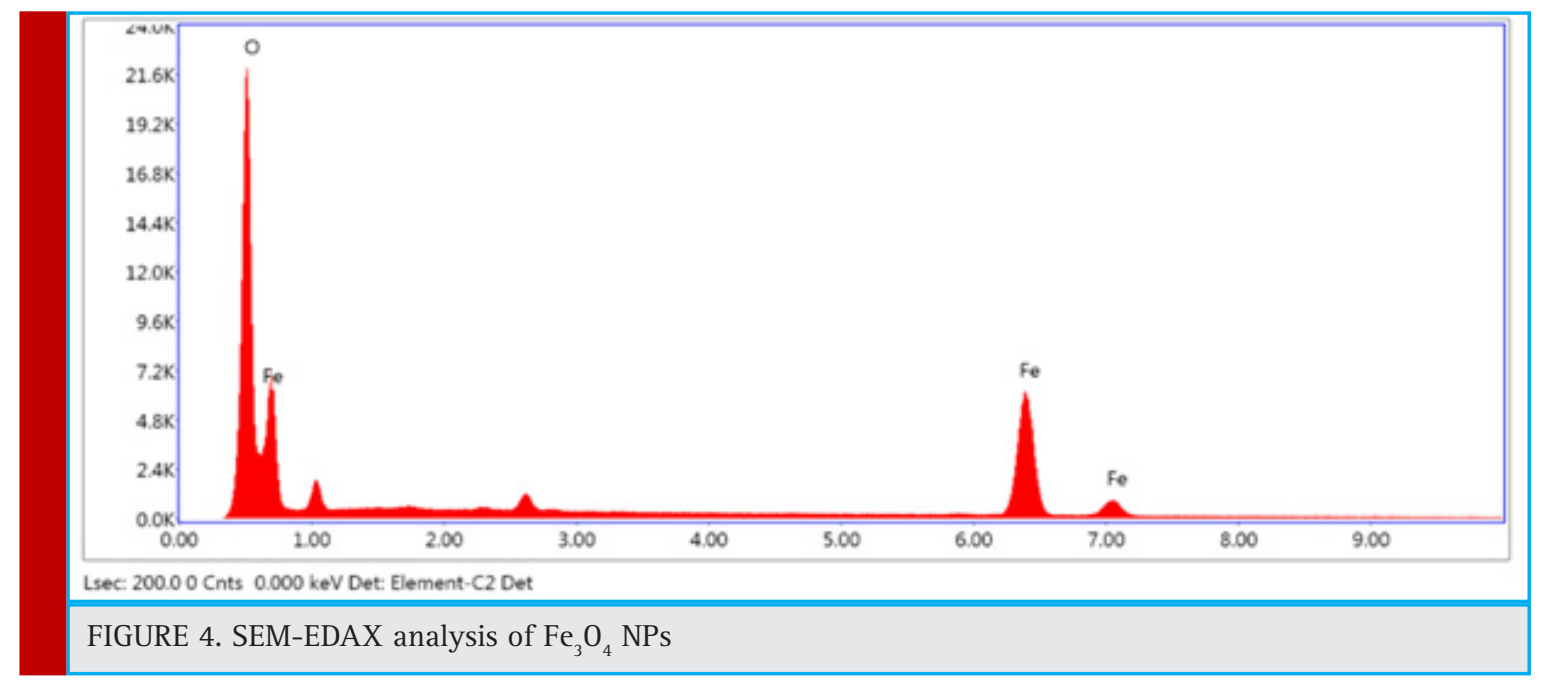

chamber which shows in Figure 4. The difference in the size of $\mathrm{Fe}_{3} \mathrm{O}_{4}$ NPs shows that the coating of gold onto $\mathrm{Fe}_{3} \mathrm{O}_{4}$ NPs was may be successful.

The analysis of $\mathrm{Au}-\mathrm{Fe}_{3} \mathrm{O}_{4} \mathrm{NPs}$ by EDAX was done to investigate the presence of $\mathrm{Au}$ and $\mathrm{Fe}$ in the synthesized nanoparticle. EDAX spectrum of the $\mathrm{Au}-\mathrm{Fe}_{3} \mathrm{O}_{4} \mathrm{NPs}$ was shown in Figure 5, which confirms the existence of $\mathrm{Au}$ and $\mathrm{Fe}$ in the synthesized nanoparticle. Hoskins et al., (2012) has reported the presence of $\mathrm{Au}-\mathrm{Fe}_{3} \mathrm{O}_{4} \mathrm{NPs}$ by EDAX analysis. Our EDAX analysis result of $\mathrm{Au}-\mathrm{Fe}_{3} \mathrm{O}_{4}$ NPs is affirmation to this.

\section{PARTICLE SIZE ANALYZER AND ZETA POTENTIAL}

In the formulation of $\mathrm{Fe}_{3} \mathrm{O}_{4}$ NPs experiments, known volumes (normally $500 \mu \mathrm{L}$ ) of $\mathrm{Fe}_{3} \mathrm{O}_{4}$ NPs suspension were taken for particle size analyzed by a Malvern Mastersizer 2000. The particle size analyzer utilizes laser technology based on the Mie light-scattering theories. $\mathrm{Fe}_{3} \mathrm{O}_{4}$ NPs was characterized to examine the particle mean size and understand the properties under different physiological conditions and also determine the surface charges of nanoparticle.

The average size of $\mathrm{Fe}_{3} \mathrm{O}_{4}$ NPs was $52.04 \mathrm{~nm} \pm 5 \mathrm{~nm}$ shown in Figure 6. The Zeta Potential of synthesized $\mathrm{Fe}_{3} \mathrm{O}_{4}$ NPs was $-31.0 \mathrm{mv}$ and polarity was negative, so it has good particle stability reflated by this result. Our result is affirmation to study of Behera et al., (2012).

\section{VIBRATING SAMPLE MAGNETOMETER}

Iron oxide (magnetic) nanoparticle may give different magnetic properties depending on condition of formulation Gupta and Gupta (2005). At room temperature iron oxide nanoparticle has superpara-magnetic property where at $60 \mathrm{emu} / \mathrm{g}$ reported for saturation. The vibrating sample magnetometer measure the iron oxide nanoparticle and gold coated iron oxide nanoparticle characteristic at $300 \mathrm{~K}$.

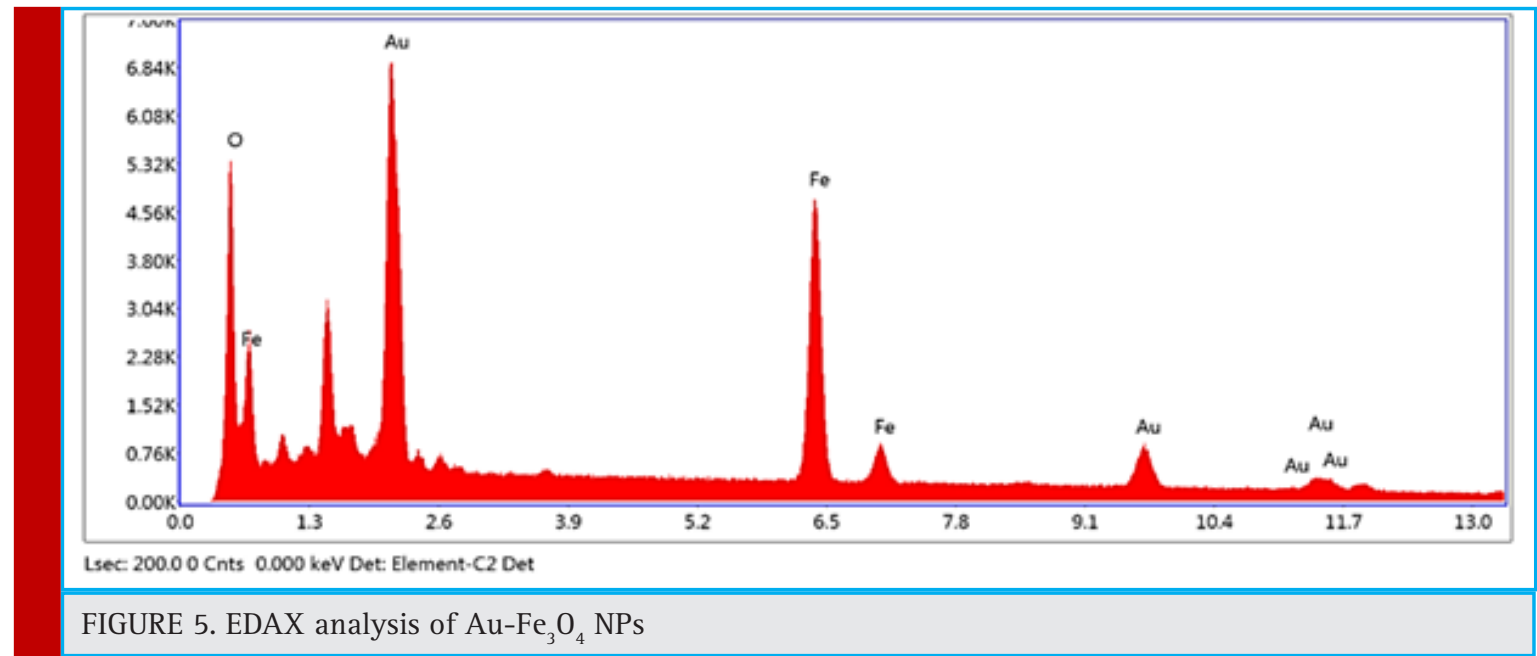




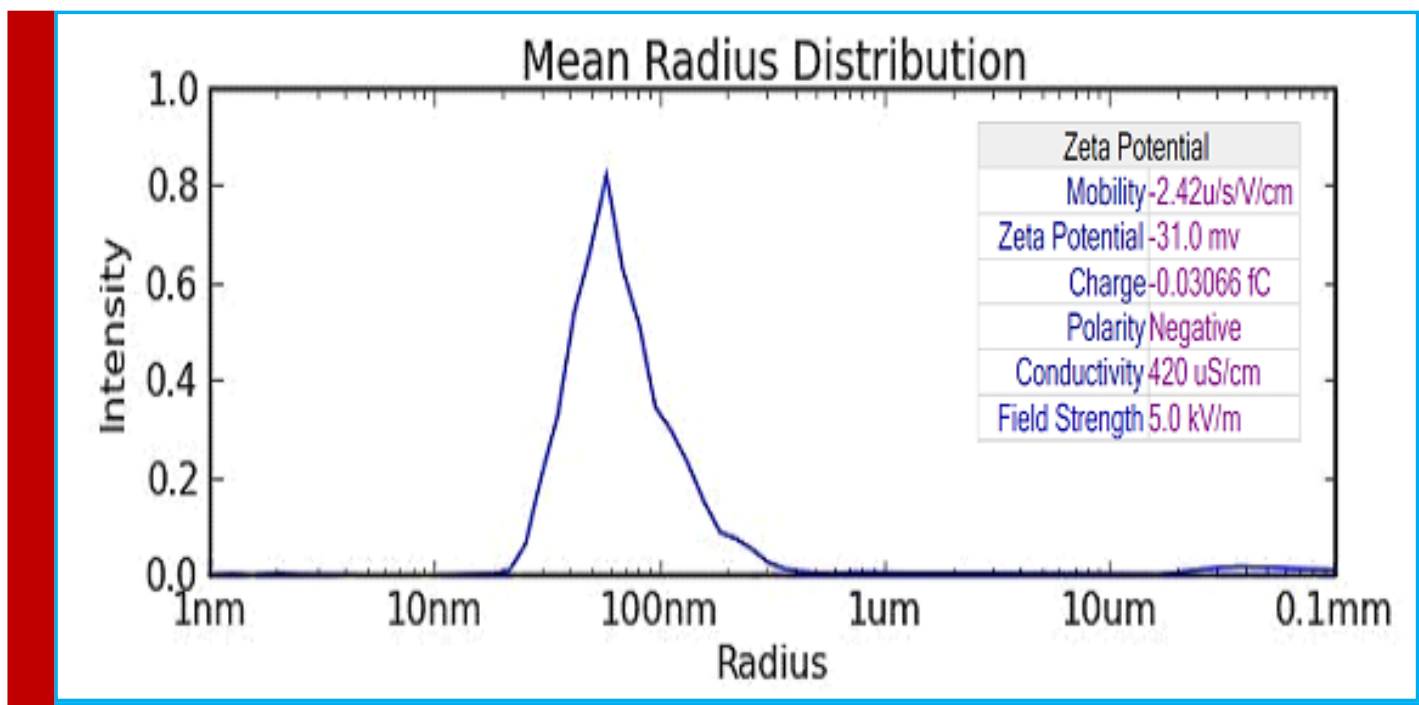

FIGURE 6. Average size of $\mathrm{Au}-\mathrm{Fe}_{3} \mathrm{O}_{4}$ NPs by Particle Size Analyzer and Zeta potential

Figure 7 shows hysteresis loop of uncoated \& gold coated iron oxide nanoparticle. The superpara-magnetism was observed in both synthesized nanoparticles. The magnetism form saturation to superpara-magnetism curve the value of iron oxide nanoparticle and gold coated iron oxide nanoparticle was 30 and $4.5 \mathrm{emu} / \mathrm{g}$ respectively at $300 \mathrm{~K}$. Reduction in magnetism was indicated that the magnetism was indicated that the formation of gold shell into iron oxide nanoparticle core.

\section{FOURIER TRANSFORM INFRARED (FTIR) SPECTROSCOPIC ANALYSIS}

The carboxylic group attached on the surface of Au$\mathrm{Fe}_{3} \mathrm{O}_{4}$ NPs by treatment of ethanolic solution having 3-mercaptopropionic acid. The activation of carboxylic group for the bonding between amide and carboxylic group, the activation of carboxylic group was catalyzed by carbodimide (EDC) in presence of N-hydroxysuccinimide (NHS). The addition of NHS catalyzed the formation of the intermediate active esters that further react with the amine function of the streptavidin (STV) to yield finally the amide bond between the monoclonal antibody aflatoxin M1 (mAFM1) and the carboxyl group on the nanoparticles.

Characteristic of $\mathrm{C}=\mathrm{O}$ and $\mathrm{N}-\mathrm{H}$ stretch analysis was done with various peaks in the FTIR spectrum region shown in Figure 8. However the sharp FTIR absorbance peaks 3426 $\mathrm{cm}^{-1}$ specific to amide indicate the presence of proteins.

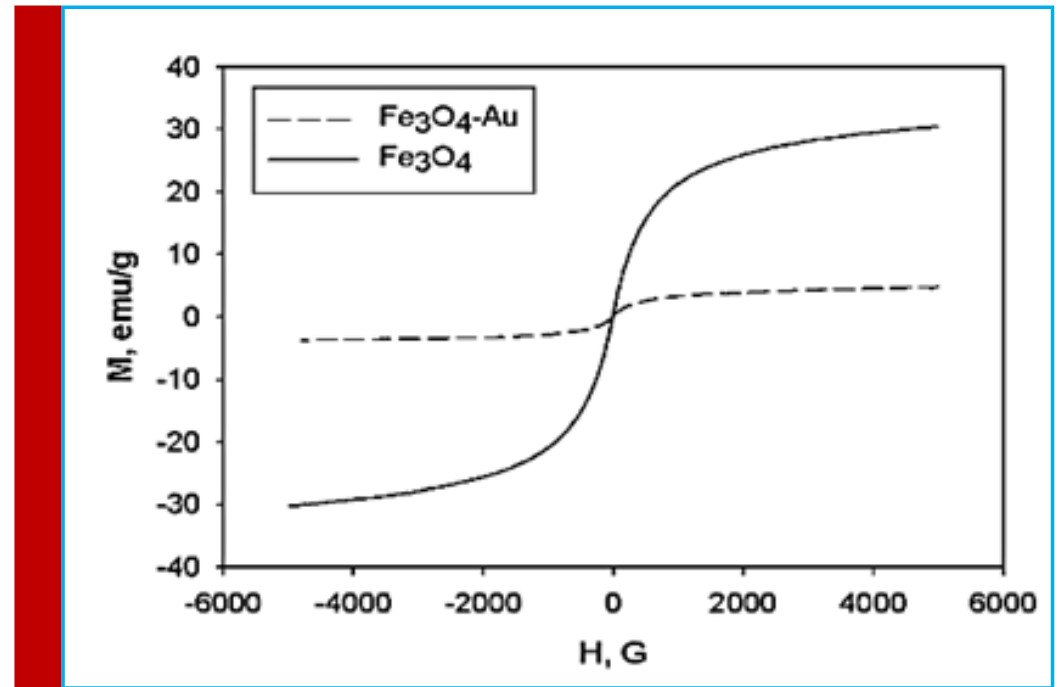

FIGURE 7. Hysteresis loops of $\mathrm{Fe}_{3} \mathrm{O}_{4}$ (solid line) and $\mathrm{Au}-\mathrm{Fe}_{3} \mathrm{O}_{4}$ (dotted line) by Vibrating 


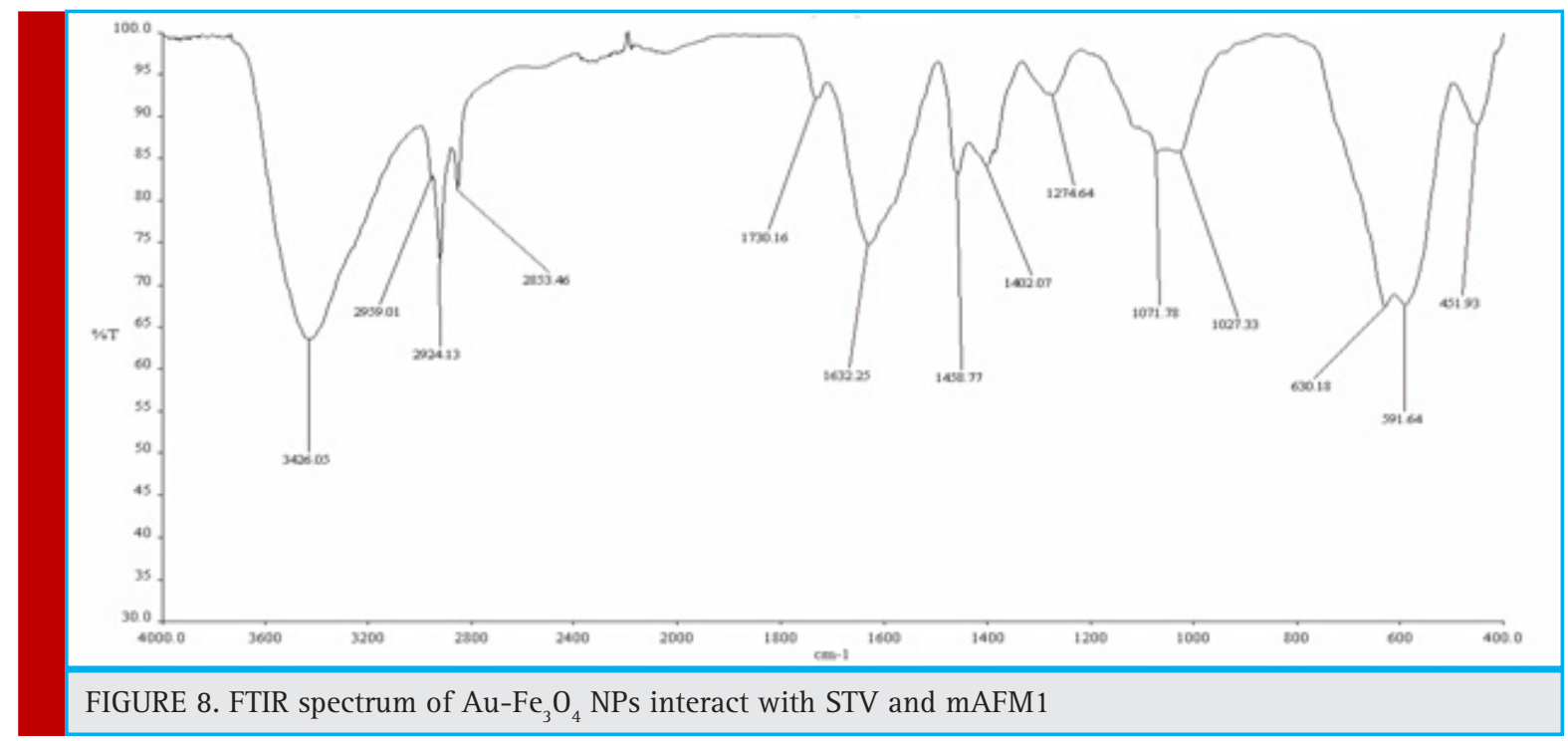

The FTIR spectrum in Figure 8 shows peaks at various ranges corresponding to different stretching and bending modes of the amine and carboxylic group. Peaks at $3426 \mathrm{~cm}^{-1}$ are assigned to N-H stretching of the amide group. The peak at $1632 \mathrm{~cm}^{-1}$ has been assigned to $\mathrm{C}=0$ stretching of the carboxylic group. The peak at 3426 $\mathrm{cm}^{-1}$ is due to $\mathrm{O}-\mathrm{H}$ stretching. This type of study has been reported previously to find functional properties, binding and to be used as detection system Adarsha et al., (2015).

\section{DETECTION OF BIOCONJUGATES BY FLUORESCENCE MICROSCOPY}

Fluorescence is a process where a fluorophore (FITC) absorb light (492nm) and turns in to an excitation form with apple green color which result in emitted light (515nm). The $\mathrm{Au}-\mathrm{Fe}_{3} \mathrm{O}_{4}$ NPs and its interaction with FITC labeled STV and biotinylated monoclonal antibody of AFM1 (bimAFM1) was measured under fluorescence microscope (Nikon Eclipse Ni) under fluorescence mode at constant flow of 50 a.u with FITC filter (EX 465-495nm, DM 505 \&t BA 512-558nm). The background of image became brighter making the particles more difficult to visualize so, it track with the Nikon D-element software.

The fluorescence microscopic image of Figure 9 (A) $\mathrm{Au}-\mathrm{Fe}_{3} \mathrm{O}_{4}$ NPs-FITC labeled STV (B) $\mathrm{Au}-\mathrm{Fe}_{3} \mathrm{O}_{4}$ NPs-FITC

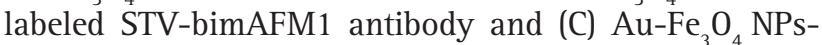
FITC labeled STV-bimAFM1 antibody-AFM1 bioconjugate was examined under fluorescence and bright field shown in Figure 9. There was no any aggregation found in case of Figure 9 (A) and (B) while in case of (C) shows the aggregation between $\mathrm{Au}-\mathrm{Fe}_{3} \mathrm{O}_{4} \mathrm{NPs}$-FITC labeled STVbimAFM1 antibody and AFM1 which indicating the successful bioconjugation. Streptavidin are used ubiquitously due to its remarkable specific binding affinity with biotin which ultimately leads to the aggregation. This aggregation could be exploited to examine at nano level due to ultra-small structure of aflatoxin M1 molecule.

The binding of bimAFM1 antibody and $\mathrm{Au}-\mathrm{Fe}_{3} \mathrm{O}_{4}$ NPs-FITC labeled STV was shown in fluorescence microscopic images. Figure 9 (A), (B) and (C) shows the green fluorescence which indicating the FITC labeled STV binding with $\mathrm{Au}-\mathrm{Fe}_{3} \mathrm{O}_{4} \mathrm{NPs}$, bimAFM1 antibody binding with $\mathrm{Au}-\mathrm{Fe}_{3} \mathrm{O}_{4}$ NPs-FITC labeled STV and aggregation between $\mathrm{Au}-\mathrm{Fe}_{3} \mathrm{O}_{4}$ NPs-FITC labeled STV and bimAFM1 antibody with AFM1. By antigen-antibody reaction anti-AFM1 and aflatoxin M1 developed color by the aggregation of gold nanoparticle conjugate Hoskins et al., (2012). Figure 9 (C) shows the pinkish red color in bright flied microscopy which confirm the aggregation $\mathrm{Au}-\mathrm{Fe}_{3} \mathrm{O}_{4}$ NPs-FITC labeled STV-bimAFM1 antibody and AFM1.M. Adarsha et al., (2015) has reported the detection of aflatoxin B1 byFe304 NPs bioconjugation. Our study is at par to this with slight difference i.e. aflatoxin M1 detection instead of aflatoxin B1.

\section{CONCLUSION}

Iron oxide nanoparticles of $10 \pm 2 \mathrm{~nm}$ has been prepared by the co-precipitation method and in a next step, the nanoparticles have been coated with gold shell of gold it confirmed by super paramagnetic properties of $\mathrm{Au}$ Fe304 shows a difference of the magnetization for the coated magnetite nanoparticles in comparison with the uncoated ones. The Fluorescence microscopic characterization shows the successful bioconjugation between $\mathrm{Au}-\mathrm{Fe}_{3} \mathrm{O}_{4}$ NPs-FITC labeled STV-bimAFM1 antibody and AFM1. 


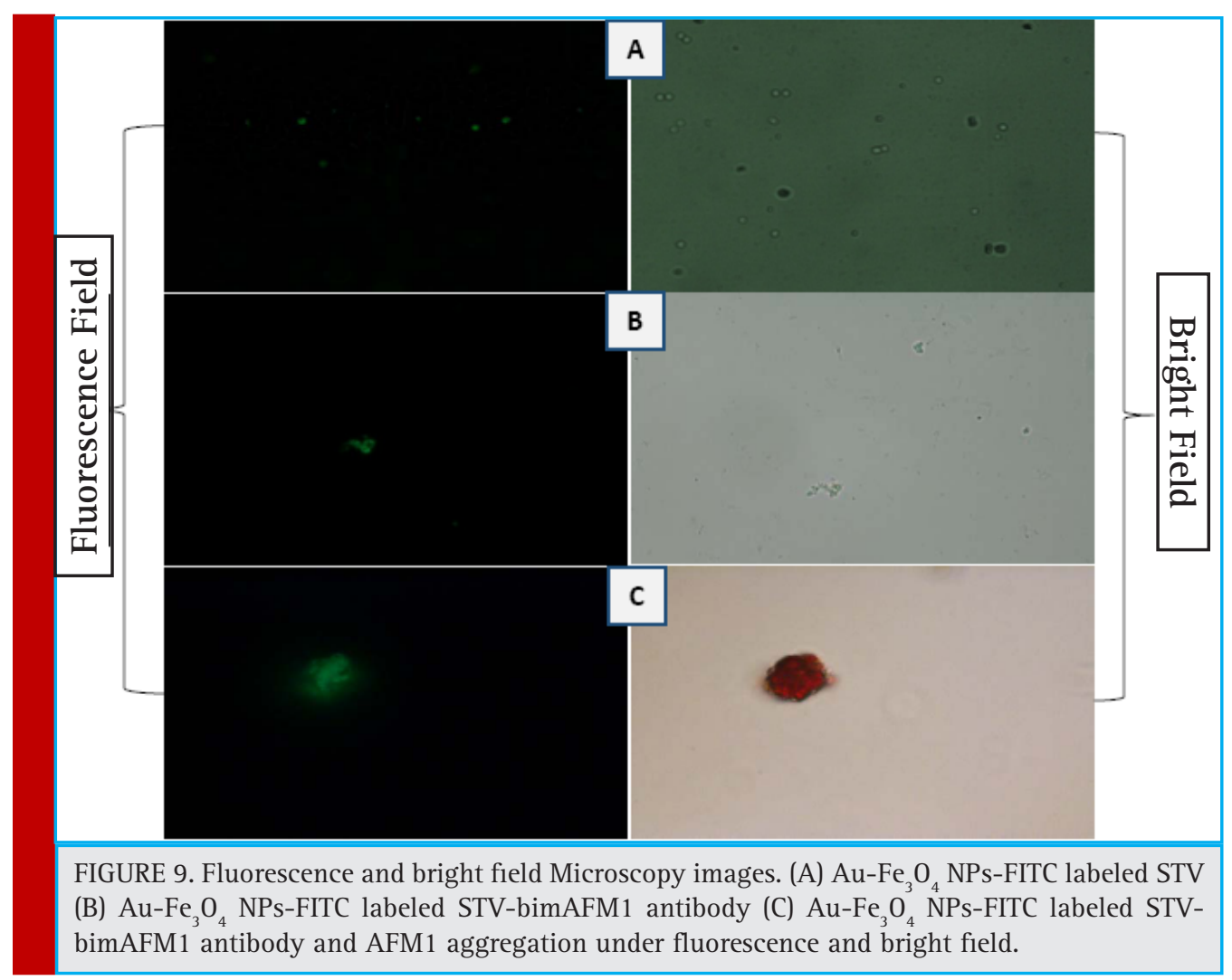

\section{REFERENCES}

Adarsha M. H., Ramani V. M. and Madhusudhan B. (2015) Development of Fluorophore Labeled Anti-Aflatoxin Antibodies Coated SPIONs for Detection of Aflatoxin B1. J. of Bionanosci. Vol. 9: Pages 94-101

Baniukevic J., Boyaci I. H., Bozkurt A. G., Tamer U. Ramanavicius A. and Ramanaviciene A. (2013) Magnetic gold nanoparticles in SERS-based sandwich immunoassay for antigen detection by well oriented antibodies. Biosensors and Bioelectronics Vol. 43: Pages 281-288

Behera S. S., Patra J. K., Pramanik K., Panda N. and Thatoi H. (2012) Characterization and Evaluation of Antibacterial Activities of Chemically Synthesized Iron Oxide Nanoparticles. W. J. of Nano Sci. and Eng. Vol. 2: Pages 196-200

Carrasco Y. R., Luana I., Anna G., Giulia G., Jordi M. and Alberto R. (2018) Simultaneous Determination of AFB1 and AFM1 in Milk Samples by Ultra High Performance Liquid Chromatography Coupled to Quadrupole Orbitrap Mass Spectrometry. Beverages Vol. 4 No 43 Pages 1-9

Eivari H. A. and Rahdar. A. (2013) Some Properties of Iron Oxide Nanoparticles Synthesized in Different Conditions. World Applied Prog. Vol. 3 No 2: Pages 52-55

Espinosa-Calderon A., Contreras-Medina L. M., Munoz-Huerta R. F., Millan-Almaraz J. R., Guevara-Gonzalez R. G. and Torres-Pacheco., I. (2011) Methods for Detection and Quantification of Aflatoxins. intechopen. Vol. 7: Pages 109-128
Flores M.E. and Gonzalez P.E. (2017) An LC-MS/MS method for multi-mycotoxin quantification in cow milk. Food Chem. Vol. 218 Pages 378-385

Gacem M. A. and Hadj-Khelil A. O. E. (2016) Toxicology biosynthesis bio-control of aflatoxin and new methods of detection. Asian Pacific J. Trop. Biomed. Vol. 6 No 9: Pages 808-814

Gretch D. R., Suter M. and M. F. Stinski. (1987) Anal. Biochem. Vol. 16 No 3: Pages 263-270

Gupta A. K. and Gupta M. (2005) Synthesis and surface engineering of iron oxide nanoparticles for biomedical applications. Biomaterials Vol. 26 No 18: Pages 3995-4021

Hoskins C., Min Y., Gueorguieva M., McDougall C., Volovick A., Prentice P., Wang Z., Melzer A., Cuschieri A. and Wang L. (2012) Hybrid gold-iron oxide nanoparticles as a multifunctional platform for biomedical application. J. of Nanobiotech. Pages 10-27

Ketney O., Santini A. and Oancea S. (2017) Recent aflatoxin survey data in milk and milk products: A review. Int. J. Dairy Technol. Pages 320-331

Kouassi G. K., Wang P., Sreevatan S. and Irudayaraj J. (2007) Aptamer-Mediated Magnetic and Gold-Coated Magnetic Nanoparticles as Detection Assay for Prion Protein Assessment. Biotechnol. Prog. Vol. 23: Pages 1239-1244

Lyon J. L., David A., Matthew F., Stone B., Schiffer P. and Williams M. E. (2004) Synthesis of Fe Oxide Core/Au Shell Nanoparticles by Iterative Hydroxylamine Seeding. Nano Letters Vol. 4 No 4: Pages 719-723 
Stroka, J. and Anklam, E. (2002) New strategies for the screening and determination of aflatoxins and the detection of aflatoxin-producing moulds in food and feed. TrAC Trends in Analytical Chemistry Vol. 21 No 2: Pages 90-95

Tamer U., Cetin D., Suludere Z., Boyaci I. H., Temiz H. T., Yegenoglu H., Daniel P., Dinçer I. and Elerman Y. (2013) Gold-
Coated Iron Composite Nanospheres Targeted the Detection of Escherichia coli. Int. J. Mol. Sci. Vol. 14: Pages 6223-6240

Tamer U., Gundogdu Y., Boyaci I. H. and Pekmez K. (2010) Synthesis of magnetic core-shell Fe304-Au nanoparticle for biomolecule immobilization and detection. J Nanopart Res. Vol. 12: Pages 1187-1196 